\title{
TOWARDS A COHERENT IMPLEMENTATION OF SAFE BUILDING LAWS AND REGULATIONS IN CAMEROON: LAW, GOVERNANCE AND INSTITUTIONAL IMPERATIVES
}

\author{
Claude Bernard Tene* \\ Siddig Omer** \\ Blaise Mempouo***
}

\begin{abstract}
Over the last decade, a sustained pattern of building collapse and fire outbreaks has been observed in various West African countries such as Cameroon, Nigeria and Ghana. This has become a matter of serious concern among building practitioners and the public authorities in these countries given the extensive loss of housing investment and human lives. The main reasons for the increased collapse of buildings include poor inspection and monitoring, structural defects, defective design/structure, illegal conversion and alterations and, most importantly, non-adherence to existing building regulations and laws. This article examines the scope of implementation and enforcement of safe building legislation and regulations in Cameroon. It identifies the existing national building regulations and the factors that limit their implementation. The article uses various data collected through questionnaires and interviews to support the finding that although there are extensive norms and regulations dealing with planning matters, there is a lack of technical building regulations and control in the country and that the existing regulations are not effectively
\end{abstract}

* PhD Candidate, Department of Architecture \& Built Environment, University of Nottingham, United Kingdom

E-mail: Claude-Bernard.Tene-Nengou@nottingham.ac.uk / teclau1@hotmail.com

** Professor at the Department of Architecture \& Built Environment, University of Nottingham, United Kingdom, E-mail: siddig.omer@nottingham.ac.uk / Lazsao@exmail.nottingham.ac.uk

*** Research Fellow,Department of Architecture \& Built Environment, University of Nottingham, United Kingdom, Email: blaise.mempouo@nottingham.ac.uk / blaise.mempouo@arpedac.org

The authors would like to thank the Association pour la Recherche et la Promotion de l'Energie Durable en Afrique Centrale (ARPEDAC) and Innovative Management \& Strategy (IMS) in Cameroon for their assistance in the data collection activities. The authors would also like to thank the interviewees and those who took part to the survey for their participation. 
implemented. Generic suggestions are made for a coherent implementation of current laws and regulation for safety in the construction industry.

Keywords: Building Policy, Building Regulations, Implementation, Safety, Africa

DOI: https://dx.doi.org/10.4314/jsdlp.v8i2.5

\section{INTRODUCTION}

The Brundtland Commission defines sustainability as the "meeting the needs of the present without compromising the ability of future generations to meet their own needs". ${ }^{1}$ In the context of building, sustainable construction refers to the development of buildings or the construction industry as a whole with serious safety considerations in mind and with a view of meeting current needs for housing, working environment and infrastructure for the foreseeable future. Currently, all building laws and policies are developed with an emphasis on this. The ideal implementation of those policies would be achieved when strategies have been adopted to deploy them on the ground effectively.Across international boundaries, the construction industry places much emphasis on safety and climate change considerations in all building projects from two floors upwards. ${ }^{2}$ Insistence on this stems from research that shows, in respect of climate change and energy consumption, that during their life cycle (from construction to demolition) buildings still consume approximately 50per cent of the total energy demand and contribute to almost 50 per cent of the greenhouse gas emitted. ${ }^{3}$ Research also shows that safety has become a key problem as buildings continue to collapse daily in various African cities. $^{4}$

1 Brian Keeble, "The Brundtland Report: Our Common Future" (1988) 4(1), Medicine and War, 17-25.

2 J. M. Kioko, "Causes of Building Failures in Africa: A Case Study on Collapsing Structures in Kenya" (2014) 11 (3), IOSR Journal of Mechanical and Civil Engineering.

3 California Integrated Waste Management Board. Designing With Vision: A Technical Manual for Material Choices in Sustainable Construction (California Environmental Protection Agency: California, CA, USA, 2000).

4 Musa Wilson, 20 March 2017. Cameroon - Littoral: Collapsed Wall Kills Three in Douala. Cameroon-Info.Net 
Consequent upon this, some West African countries such as Cameroon, Nigeria ${ }^{5}$ and Ghana ${ }^{6}$ have embarked on a sustainability mission reflected in the national statutory instruments and policies in all sectors. For example, over the years, policymakers in Cameroon have developed several policies in order to improve the building practice and to drive the country towards meeting its safety and sustainable objective. ${ }^{7}$ The building sector in Cameroun is regulated by a number of tools ranging from statutory instruments such as acts of parliament to ministerial guidelines, ordinances and local bylaws, which mainly contribute to guiding development in towns and cities. This regulatory mechanismincludes the use of land and buildings, their appearance, landscape, highway access and the impact of construction on the environment.

The overall aim of the government is to regulate the erection and destruction of buildings, the alteration of their structure and to ensure that buildings constructed in the urban areas are sustainable and safe for the occupiers and for those working within the construction sites. Most of those laws and regulations have been in existence from the late 1940s, with fewer added later on.

However, effective implementation of these laws and regulations remains challenging for several reasons. Among these are that the housing construction system must ride through several institutions, bothpublic, para-public and informal. ${ }^{8}$ Those institutions all have overlapping processes affecting their effective implementation. Those overlaps, the complex pyramidal structure of the country's administration and the lack of coordination between the institutions render the implementation of existing regulations difficult to follow and to deploy in its entirety.

Meanwhile, the regulations of the building sector belong to several agencies whose principal responsibility is to "ensure that housing and

5 S.A. Oloyede, "Tackling Causes of Frequent Building Collapse in Nigeria" (2010) 3(3), Journal of Sustainable Development.

6 Ametepey \& Ansah, "Significant Factors Affecting the Implementation of National Building Regulations L.I.1630 by Local Authorities in Ghana" (2015) 5 (2), Public Policy and Administration Research.

7 Tchamba \& Bikoko, "Failure and Collapse of Building Structures in the Cities of Yaoundé and Douala, Cameroon from 2010 to 2014" (2016) 10 (1), Modern Applied Science.

8 Njoh Ambe, "The Institutional Framework for Housing Policy Administration in Cameroon" (1992) 16(3), HABITAT INTL, 43-57. 
land development is carried out strictly in accordance with all applicable by-laws. ${ }^{9}$ They are placed mostly (but not only) under the watchful eye of the Ministry of Housing and Urban Development (hereafter MINDUH). However,concerning the development and implementation of the various policies and instruments in the construction industry in general several other ministries, such as the Ministry of Health, the Ministry of Territorial Administration, the Ministry of Energy and the ministry in charge of the environment, also have significant powers.

It must be emphasized that coordination between all the ministries in the building process is very poor. This can be seen at the policymaking level, the regulatory level and during the implementation of various policies, which inevitably results in poor application and enforcement of existing laws and regulations. This situation raises further concerns about the nature of policy development in the country in general and in building construction in particular. In this latter field, specifically, it has been observed that building failures and consequent collapse of structures in Cameroon have reached an alarming rate over the past few years. ${ }^{10}$ These findings and the policy arrangements within various ministerial departments may be contributors to those failures.

This article examines the current situation and makes suggestions that could lead to a coherent implementation of building laws and regulations in the country. To bring illumination to the problems, the article presents the methodology adopted, the data gathered through the questionnaires and interview of various stakeholders, the analyses conducted on the data and the discussion of the proposed solutions to the issues identified as affecting the effective implementation of existing building laws and regulations in the country.

\section{METHODOLOGY}

A desktop review of journal articles, laws and books were undertaken, and then, surveys and interviews were used to gather the subjective views of the stakeholders in the Cameroonian building sector. The stakeholders are building construction practitioners, owners, occupiers and local authority staff. We sought the views of these people on current building regulations and implementation. The focus on opinions over

9 ibid.

10 Tchamba \& Bikoko (n 7). 
a representative sample of all stakeholders of the building industry enables this research to identify the reasons affecting the implementation of existing building regulations in order to trigger ideas as to how to enhance the implementation of any modern building rules and regulations in the country.

The deductive reasoning method was used to deconstruct the materials gathered and analysed in this study. Participants were recruited amongst all categories of stakeholders to ensure that the data collected includes perceptions from each category. A large number of participants was deliberately chosen in each category to ensure a balanced contribution, as the literature was sparse in this specific research area in Cameroon.

\subsection{Building Laws and Regulations in the Context of Implementation}

The desktop review of the existing laws and regulations of the country ${ }^{11}$ highlights a high level of activity within the planning side and the lack of relevant action on the regulation of the technical side of building constructions in the country. Various newspapers report regular fire outbreaks and building collapses as evidence of non-respect for, or poor implementation of, existing building regulations rather than a consequence of the absence of such regulations. ${ }^{12}$ In fact, regulation in the building sector dates back to the colonial era. For instance, our literature review shows that urban planning in Cameroon was organized immediately after the Second World War and by 1966 the national parliament had passed the Law No 66/10 of 18 November 1966, which laid down the urban planning regulations for the French-speaking part of the land. ${ }^{13}$ According to extant literature, that law came into force promptly with the implementation of a decree passed by the prime minister on 27 March 1968. That initial law was in place until the reunification of western and eastern Cameroun in May 1972.

Upon the reunification of Cameroon, the planning law was revised

11 Gouvernance Local: Le Guide de Reference, Tome1, Tome2, Tome3; 2011 Ministère du développent Urbain et de l'habitat \& Ministère de l'administration territorial et de la décentralisation. République du Cameroun.

12 Guebediang à Bessong Sorele, «Un autre immeuble s'effondre' Cameroon Tribune» $\left(\mathrm{N}^{\circ} 11114 / 7313\right.$ of 13 June 2016).

13 Le Guide de Reference (Gouvernance locale, Tome1 Urbanisme opérationnel, 2011) 8. 
in 1973 and the Ordinance No. 73/20 regulating urban planning in the United Republic of Cameroon was enacted in replacement of the 1966 law. It is observed that despite the existence of that planning law, there was no change in building practices as people continued to build without regard for the existing planning laws. In fact, it was noted in 1989 that in breach of the 1973 ordinance, which required all local councils to develop and implement their specific town planning documents, most of the councils failed to put their procedures in place.

The data available at the MINDUH reveals that in 1989 only 11 councils had an approved Town Plan. ${ }^{14}$ The situation persisted and became critical in early 2000.This prompted the government to call for an updated regulation geared towards sustainability. That action led to the introduction to the parliament of a White Paper, which in turn led to the enactment of the "Urbanism Code", a building Law No. 2004/ 003 of 21 April 2004 regulating Urban Planning in Cameroon. ${ }^{15}$ Despite the dire situation on the ground, the government took four years to issue the full implementation decrees. (They finally happened in 2008.) Those decrees are: (a) Decree No. 2008/0736/PM laying down conditions for drawing up and revising town planning documents; (b) Decree No. 2008/0737/PM laying down safety, hygiene and sanitation rules applicable to construction works; (c) Decree No.2008/ 0738/PM organizing land-use procedures and processes; (d) Decree No.2008/0739/PM laying down land-use and construction rules (replaced by Decree No.2016/3058/PM of 28 July 2016) and (d) Decree No. 2008/0740/PM setting rules on penalties in the event of breach of town planning rules. This law is currently the main regulatory tool in terms of planning in the country. Another important instrumentis Law No.98/015 of 14 July 1998 relating to institutions classified as dangerous, improper or incommoded.

The government has since continued to show its willingness to improve the legal landscape of the building sector and accordingly the MINDUH ${ }^{16}$ has passed several ordinances with a view of correcting the

14 Gouvernance Local: Le Guide de Reference, Tome1, Tome2, Tome3; 2011 Ministère du développent Urbain et de l'habitat \& Ministère de l'administration territorial et de la décentralisation. République du Cameroun.

15 Guebediang à Bessong Sorele, «Un autre immeuble s'effondre' Cameroon Tribune» $\left(\mathrm{N}^{\circ} 11114 / 7313\right.$ of 13 June 2016).

16 Le Guide de Reference (Gouvernance locale, Tome1 Urbanisme opérationnel, 2011) 8. 
inadequacies observed in practice and in order to harmonize the national procedures and documents required for town planning applications. Those ordinances are summarized as follow: Ordinance No. 0005/E/2/MINDUH of 23 May 2011 establishing a model for town planning application certificate; Ordinance No. 0002/E/2/MINDUH of 23May 2011 establishing a model for building permit applications, and the Ordinance No. 0005/E/2/MINDUH of 23May 2011 establishing a model for a works completion statement and compliance certificate.

Alongside the above legal instruments are other regulations drawing directly on the authority of the MINDUH as well as other instruments placed under the authority of the Ministry of Environment such as Law No. 96/12 laying down the framework on the management of the environment with its implementation Decree No. 2005/0577/ PM; Law No. 89/27 regulating toxic waste, and Law No. 98/005 concerning the water regime .Others are Order No. 0070/MINEP, by the Ministry of Environment and Nature Conservation, fixing the different categories of operations subject to an impact assessment prior to their execution; Law No 98/006 relating to tourist activity and its execution decree No. 99/443/PM.

In practice, it is very difficult to reconcile how the different parts of these laws relating to building constructions are implemented. That is also the situation with instruments under the control of the Ministry of Energy, such as Law No. 2011/022 governing the electricity sector, the oil code enacted under Law No 99/013 and its implementation decrees No. 2000/465, and Law No. 2012/006 relating to the gas code. Various other instruments that are relevant to the building sector but depending upon other various ministries also exist and cannot be individually identified given the inadequate filing system.

Despite these plethora of laws and regulations confirming the initiatives taken by the government to establish a sound legal framework in the building sector of the country, it is observed that effective implementation of those instruments remains questionable and falls far short of the rigour and minimum standards observed in nearby countries such as Nigeria and Ghana. That inadequacy shows up in the continued collapse of buildings ${ }^{17}$ and fire outbreaks, ${ }^{18}$ which grow year after year.

171 Tchamba \& Bikoko (n 7).

18 http://www.cameroonweb.com 
Whilst efforts have been made to regulate urbanization and planning in the country, it is noted that the technical aspect is not effectively controlled. Indeed the technical standards are dealt with under the global blanket of ISO $^{19}$ standards with no real effort to calibrate them to the specific situation of the country. The government has attempted to correct this insufficiency by creating in 2009 the National Cameroonian Standards and Quality Agency (ANOR), ${ }^{20}$ which is affiliated with the ISO. The former's main aim is to provide solutions to the challenges facing the country by setting the technical standards of various products, including the standards within the building construction sector.

In the exercise of its powers, ANOR has developed a number of standards including those applicable to the building sector such as on fire prevention, equipment installation, electrical installations, testing in various areas including environmental protection in building, gas, concrete and so on. Even though all those standards mirror the International Standards, they are expressly said to be discretional, and therefore no penalty applies for failure to abide by them. ${ }^{21}$

A deep review of existing building laws and regulations in Cameroon shows that without a real building code dealing with the technical and normative standards it is impossible to efficiently regulate the sector let alone to ensure the implementation of the existing rules. They are too broad, too vague and scattered. The confusion escalates as the urban population is expected to accrue at an exponential rate, similar to other sub-Saharan African countries unless adequate steps are taken to put together a modern and adequate building code. The current laws are primitive and wholly inappropriate, particularly in the era of globalization and where the fight against global warming is consciously carried out everywhere, including through improvementsin building construction practices.

\subsection{Data Collection and Participants}

The data was collected in three phases. Initially, a full desktop review of current building laws and regulations in the country took place, along with the review of statutes and various journal and newspapers articles on building regulations.

19 International Organisation for Standardisation.

20 www.anorcameroun.info

21 Anor cameroun, (2017) http://www.anorcameroun.info/ 
The review was followed secondly by a survey. Questionnaires were categorized into several themes and distributed online as well as on paper to 30 selected building practitioners, 20 selected staff of the central or local authorities, 25 selected building operators or occupiers and 25 selected building owners. Participants in each category were randomly recruited from four main regions of the country, Centre, Littoral, West and Northwest.

Phase three of the data collection involved the conduct of semistructured interviews with an architect, an officer of the MAETUR (a government's national land settlement agency), a high-ranking civil servant of the technical department of the MINDUH and a building owner in Yaoundé. This was done to deepen the analysis of the findings from the technical and professional perspective. The semi-structured interviews were broadly designed to target the same topics and issues as those appearing in the questionnaires. The aim was to allow follow up questions and discussions in order to have a better understanding of the dominant positions held by professionals. The interview records were subsequently transcribed by the researcher and translated into English by a sworn translator. In all, 103 stakeholders participated in the study and the details are shown in Table 1.

The purpose of the questionnaires and interviews was to establish the nature of existing policies, laws and regulations in the building construction industry in Cameroon and to consider the factors affecting their implementation in practice. The main outcomes of the interviews were the participants' assessment of the adequacy of current laws and regulations as well as the problems of implementing them effectively.

\subsection{Data Analysis}

Four sets of questionnaires were developed for data collection and specifically targeting at different stakeholders. The first set targeted the building owners and was structured to gather information on their building, their experience as perceived during the construction phase of the building, their perception on regulations and compliance and their familiarity and usage of technology in their building.

The second set was addressed to building occupiers and operators and structured to gather information on their level of comfort, the safety of the building, their views on the national building regulations and compliance levels as well as their level of acquaintance with and usage of building technologies. The third set targeted building practitioners (architects, engineers, surveyors) and was structured to 
Table 1. Questionnaires Distributed/Interviews Conducted and Replies Received

\begin{tabular}{lcccc}
\hline & $\begin{array}{c}\text { Questionnaires } \\
\text { distributed \& } \\
\text { interviews } \\
\text { conducted }\end{array}$ & $\begin{array}{l}\text { Responses } \\
\text { returned }\end{array}$ & $\begin{array}{c}\text { Percen- } \\
\text { tage } \\
\text { Responses }\end{array}$ & Observations \\
\hline $\begin{array}{l}\text { Building } \\
\text { practi- } \\
\text { tioners }\end{array}$ & 32 & 29 & 90.63 & $\begin{array}{l}\text { Including 2 } \\
\text { interviews }\end{array}$ \\
$\begin{array}{l}\text { Building } \\
\text { owners }\end{array}$ & 26 & 21 & 80.77 & $\begin{array}{l}\text { Including 1 } \\
\text { interview }\end{array}$ \\
$\begin{array}{l}\text { Building } \\
\text { occupiers/ } \\
\text { operators }\end{array}$ & 25 & 21 & 84.00 & \\
$\begin{array}{l}\text { Central \& } \\
\text { local } \\
\text { government } \\
\text { staff }\end{array}$ & 21 & 17 & 80.95 & $\begin{array}{l}\text { Including 1 } \\
\text { interview }\end{array}$ \\
\begin{tabular}{l} 
Total \\
\hline
\end{tabular} & 103 & 87 & & \\
\hline
\end{tabular}

Source: Author's qualitative data collection.

collect information about causes of non-compliance with building regulations and standards, their practices and continued professional development as well as their views on the usage of technologies in everyday practice.

The fourth set, aimed at central and local authority employees, was also structured in a way that facilitated data collection on building regulations and processes, causes of non-compliance with extant laws, how to solve the problems of the building sector and how to develop further in their profession.

The four sets of questionnaires submitted to participants were returned through the secure password protected Bristol Online survey tool, and the Bristol online software was used for computations and analysis of the answers received. This software enables the researcher to develop the questionnaires and to put them in a protected space online where they can be accessed using a secret password. Once the questionnaire is developed participants are invited to access it online 
and to complete it using the passport given by the researcher. The data are therefore collected and kept securely for the research team's review.

The questionnaires gathered led to a quantitative analysis of the answers reported in the form of graph and pie charts through the Bristol online software. The descriptive method used for analysing the questionnaires is presented in percentages, means scores and ranking of some targeted factors and values.

The interviews furnished qualitative data which were collated according to the frequencies of responses. A qualitative method was therefore fully applied to analyse the transcript of the semi-structured interviews, that is, using thematic content analysis. This is done by coding data by themes based on currently known theories (deductive coding) and from the content of the data gathered (inductive coding).

To enhance the depth and understanding of the data, the analysis was also achieved by grading responses as frequently recorded (appearing at least twice in each of the four interviews when discussing the relevant topic), commonly recorded (appearing at least twice in two of the interviews when discussing the relevant topic) or infrequently recorded (appearing in only one of the interviews when discussing the relevant issue). Identified quotes from interviewees that provided a brief description of their perception of the national building construction policy development, the factors affecting the implementation of current building laws and regulations and of proposed solutions were also recorded.

\section{RESULTS AND DISCUSSION}

\subsection{The Building Laws and Regulations}

The review of the laws and regulations identified above shows that it was important to find out whether the country actually has building regulations. To answer that question, it is important to distinguish between building and planning regulations. It should be noted that in practice:

Building regulations set standards for the design and construction of buildings to ensure the safety and health of people in or around those buildings. They also include requirements to ensure the conservation of fuel and power and that facilities are provided for people, including those with disabilities, to access and move around inside the buildings (An interviewee's response). 
Planning laws seek to guide the way towns, cities, and country sides develop. They include the use of land and buildings, the appearance of buildings, landscaping considerations, highway access and the impact that the development will have on the general environment. ${ }^{22}$ Drawing from this difference and bearing in mind the nature of the Cameroonian laws reviewed above, it clearly means that whilst a lot of regulations exists on planning, there are no clearly set out standards in the building construction sector.

ANOR has attempted to define standards mirroring those set by the existing ISO, however as far as the building construction sector is concerned the standards coded are insufficient and not compulsory. In practice, all stakeholders tend to ignore standards, which has been identified as one of the key causes of persisting building collapse. In 2014 alone, within a few suburbs of Douala and Yaoundé, 36 cases of building collapses were recorded and the main causes found to be the non-observation of building standards. ${ }^{23}$

Regarding policy development and implementation in the country, respondents blame the ensuing confusion on the lack of coordination between the administrative agencies and the parliament, leading to a needless complexity of the policy environment and the involvement of various ministries, regions and local authorities in policy implementation.

The building policies are developed linearly and in a strictly topdown fashion. In addition to being unclear, these policies are prescriptive and forced upon stakeholders without their input. For the sake of clarity, the complex administrative structure of the country and bodies involved in the development and implementation of building policies are highlighted in Figure 1.

\subsection{Ineffective Implementation of Existing Building Laws and Regulations}

The respondents were specifically invited to discuss a number of issues surrounding the building industry in the country with specific emphasis on policy, laws and regulations and their implementation.

The responses gathered from the questionnaires and interviews are summarized in Figures 2.1-2.4 and show a sufficient level of

22 Planning Portal, 2017 https://www.planningportal.co.uk/ 23 Tchamba \& Bikoko (n 7). 


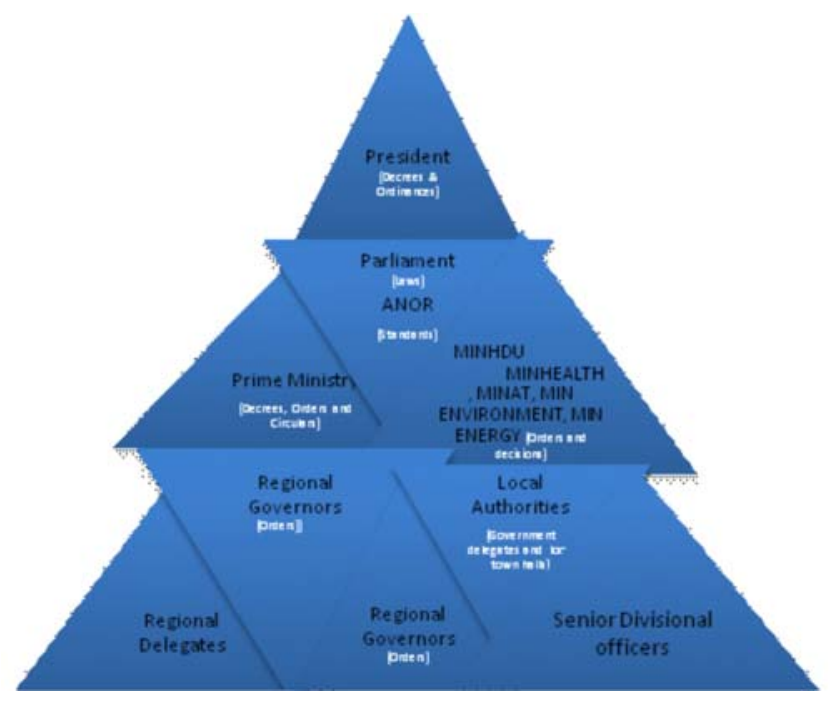

Figure 1. Administrative Structure of Building Policies in Cameroon

Source: Illustrated by authors.

agreement between the stakeholders that the current building laws, regulations and policies are not observed or are inappropriately applied and/or poorly implemented.

For instance, the four groups of stakeholders were asked whether professionals and owners fully comply with building regulations and planning laws in general. They overwhelmingly and openly conceded that they did not (Fig 2.1). Also, the chart shows that only 25 per cent of building owners declared that they were aware of the building laws and regulations but amongst them only 58 per cent thought that practitioners abided by them.

To the same question the majority of employees of the central and local government subjectively assessed that practitioners did not observe the regulations themselves (56.3 per cent) as opposed to 37 per cent who thought that they did. Most practitioners in the survey (60 per cent) claimed that they complied with regulations as against 37 per cent who said they only complied with the regulations occasionally and 4 per cent who openly admitted that they never attempted to comply. To that same question, the building occupiers overwhelmingly stated that practitioners did not abide by the regulations with a majority of 75 per cent holding such view. 


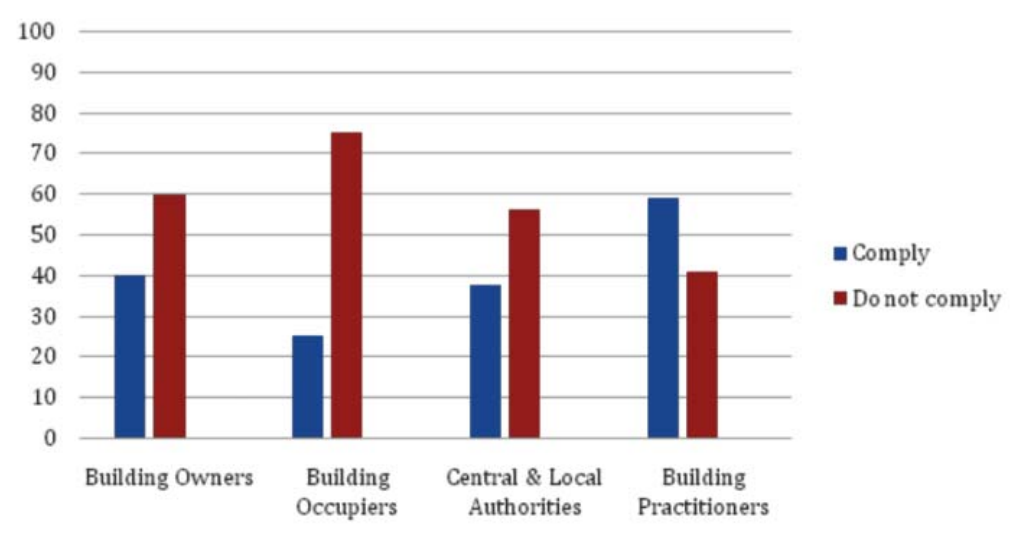

Figure 2.1. Stakeholders Perception on the Practitioners' Level of Compliance with BR

Source: Author's Descriptive Data.

\subsection{Stakeholders do not Observe the Regulations in their Current State}

A majority of local authority employees (93.8 per cent)confirm that builders all those in charge of building sites do not apply for nor do they obtain a permit before they start their building works, a point that 80 per cent of building owners themselves readily admitted (see Figure 2.2).

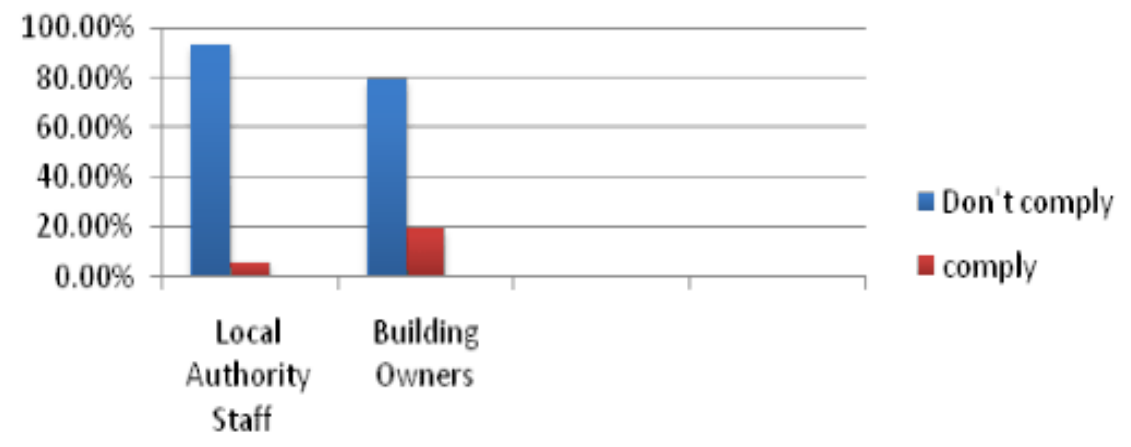

Figure 2.2. Do Practitioners Obtain Building Permits Before they Start Construction Work?

Source: Authors' Descriptive Data Results. 
This disappointing finding shows that all stakeholders in the building industry agree that building practitioners who should be the force behind compliance and implementation do not themselves observe the existing building laws and regulations. The hypothesis that the existing laws and regulations are not effectively implemented in the country is, therefore, confirmed as evidenced in Figure 2.3.

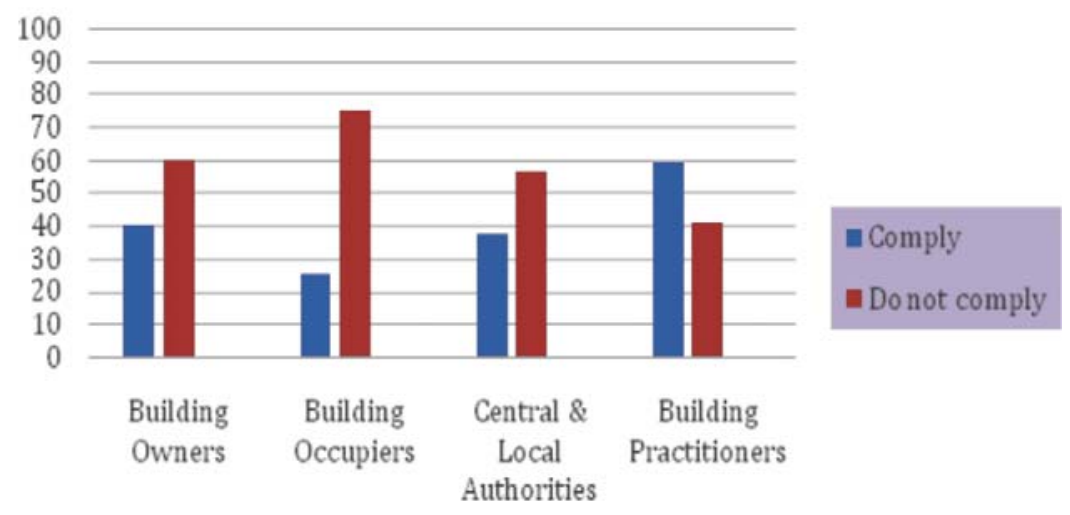

Figure 2.3. Stakeholder's Perception on the Level of Professional Compliance with BR

Source: Authors' Qualitative Results.

\subsection{Self-Constructions without Professionals' Input Impair Compliance}

Given the initial response from stakeholders in the uilin industry, it is not surprising to garner from the data that more than two-thirds of buildings in Cameroon were self-built without the input of any professional whatsoever. Some 66.7 per cent of the respondents agreed to this compared to 22.2 per cent who said they used the services of at least a professional. Their responses of these building owners are highlighted in Figure 2.4.

\subsection{Ignorance and Lack of Professional Training Impair the Implementation of Existing Laws and Regulations}

A major factor affecting the implementation of building and planning laws and regulations in the country appears to be the stakeholders' 


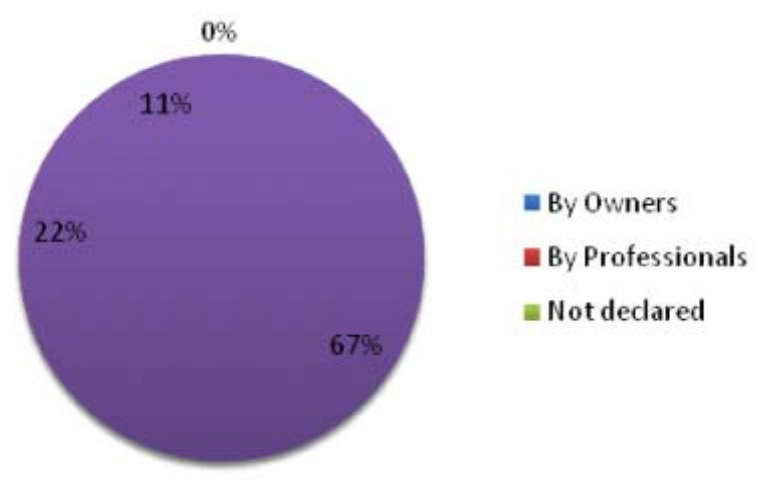

Figure 2.4. Building Owners' Responses on Who Constructed their Building Source: Authors' Qualitative Analysis.

lack of awareness of those laws. The building owners overwhelmingly conceded in the survey that they were not aware of the norms/ standards required for building construction in the country (75 per cent) as against 25 per cent who claimed to be familiar with the standards. Interestingly, 58.3 per cent of those who claimed to be aware of the standards still refused to comply with them, compared to 25 per cent who partly complied.

In all, only 8.3 per cent of respondents fully complied with the law while another 8.3per cent did not know whether they had complied with the regulations or not. The central and local authorities reinforced this position as 56.3 per cent of them said building practitioners do not abide by the existing building and planning laws as opposed to 37.5 per cent who claimed they do.

If practitioners are unwilling to obey building regulations, then it wouldn't matter too much whether they know the laws or not. Nevertheless, when asked about familiarity with the country's main current building laws and regulations, only 38.4 per cent considered themselves familiar with the Urbanism Code, against 28.8 per cent who claimed to be familiar with the secondary source of law which is the prime minister's circular of 2007 on the use of local materials.

Only 19.2 per cent of the participants admitted to being fully aware of the various regulations setting out modalities for the planning documents. The score was even lower for the 1974 ordinance governing land tenure, as only 13.5 per cent of participants were familiar with that regulation. This trend provides clear evidence that regardless of 
the quality and quantity of the existing laws and regulations in the building field, the majority of practitioners simply carryon their work regardless of the law. And if this level of non-compliance is anything to go by, it should not be surprising that building collapse has become commonplace in the country. Figure 2.5 summarizes the building practitioners' (non-)familiarity with the main instruments that govern their practice.
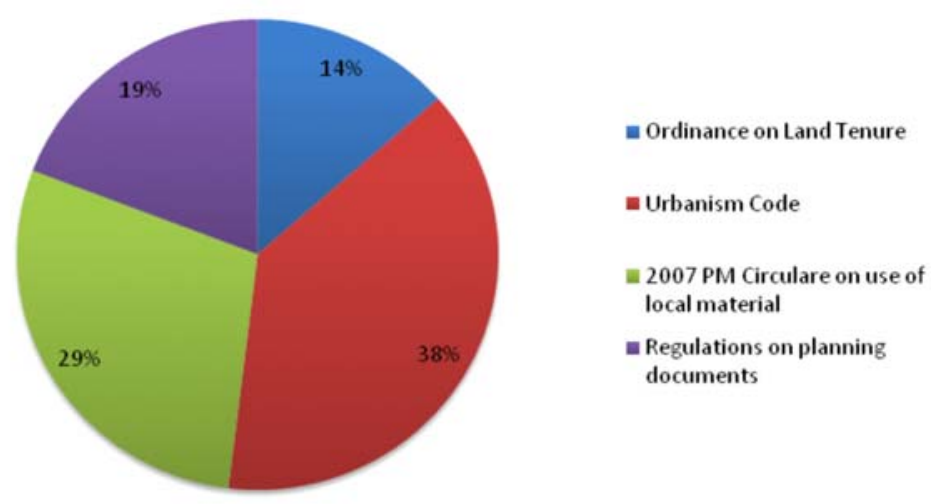

Figure 2.5. Practitioners' Familiarity with the Main Building Laws and Regulations

Source: Authors' computations from the survey.

This same trend is confirmed when the practitioners were asked about their level of compliance with the building laws and regulations in general. The majority of building (almost 60 per cent) admitted that they only observed the laws occasionally, while 37 per cents aid they often did.

It was also established in the survey that most people who called themselves practitioners in building had no requisite training. For instance, 19.2 per cent never attended any training on building standards or on planning laws and regulations and those who did (another 19.2 per cent), had their training more than two years before. Of those who had some training, 26.9 per cents aid it was less than two years and 34.6 per cents aid it happened within the previous 12 months. The overall finding is summarized in Figure 2.6 and confirms the poor training profile of building practitioners in the country. It follows that if they had little or no training they might also not be aware of the extant laws. 


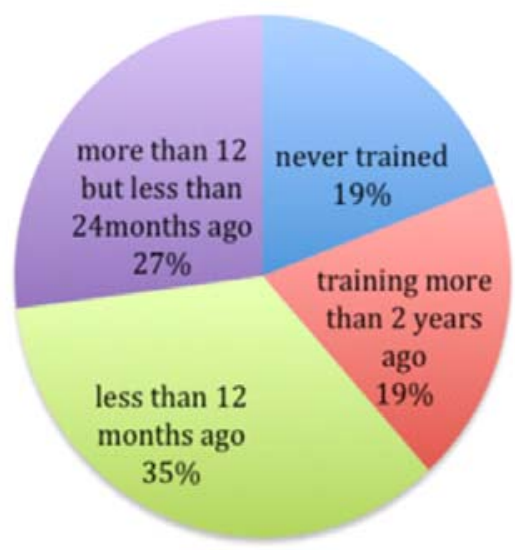

Figure 2.6. Timing of Practitioners' Last Training

Source: Authors' analysis from the survey.

Elsewhere the data gathered also projects that amongst the factors affecting the implementation of the existing building laws and regulations the government's top-bottom strategy was a catalyst for the poor success rate. Indeed, building practitioners were critical of the government actions as almost 70 per cent argued that it is counterproductive to develop policies and to force them upon the stakeholders.

Those who were critical of the lack of collaboration were asked which of government's action would most likely lead to greater implementation of existing building laws and regulations in their views. About 39.6per cent suggested that specific actions to educate all stakeholders would significantly raise the level of implementation. Putting in place a framework for regular consultations or discussions with the stakeholders and ensuring a strict enforcement regime were identified as other suitable ways by 28.3 per cent of the respondents.

\subsection{Other Identified Causes of Poor or Non-Adherence to Existing Regulations}

Overall, when asked to consider the main causes of poor or nonadherence to building regulations, the stakeholders, regardless of their respective categories, agreed that the lack of awareness of the existing laws and regulations by them was the most likely source of the problem. Those findings are highlighted in Figure 2.7 and show that 75 per cent of employees of the centralor local authorities took that view compared 
to 68.4 per cent of building owners, 66.66 per cent of building occupiers and 36 per cent of building practitioners. In the same Figure 2.7, respondents identified corruption as the most likely cause of noncompliance with 44 per cent of local and central authorities employees supporting this view compared to 33.33 per cent of building owners, 28.57 per cent of building occupiers and 37 per cent of practitioners. All categories of stakeholders agreed that other causes of noncompliance with regulations included inadequate penalties for the violations, lengthy and high costs of administrative procedures, insufficient personnel and political interference. The various levels of compliance are also highlighted in Figure 2.7.

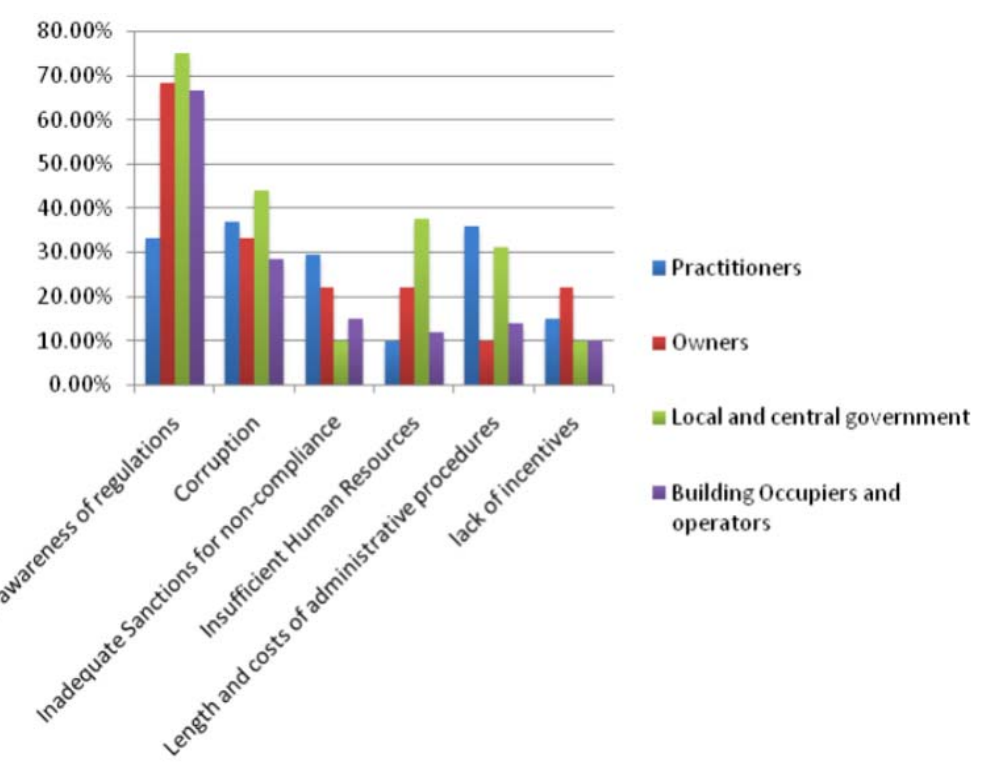

Figure 2.7. Causes of Non-Compliance by all Stakeholders

Source: Author's qualitative analysis.

The staff of the central and local authorities who bear prime responsibilities for the implementation of the regulations and policies were very critical of the situation on the ground. They blamed the difficulty of accomplishing their jobs on seven reasons, namely, inadequate training (33.33 per cent), shortage of personnel (26.66 per cent), and poor awareness of the laws (13.33 per cent). Other reasons adduced included corruption (6.66 per cent), administrative 
bottlenecks (6.66 per cent)and lack of transport means (6.66 per cent) (see Figure 2.8).

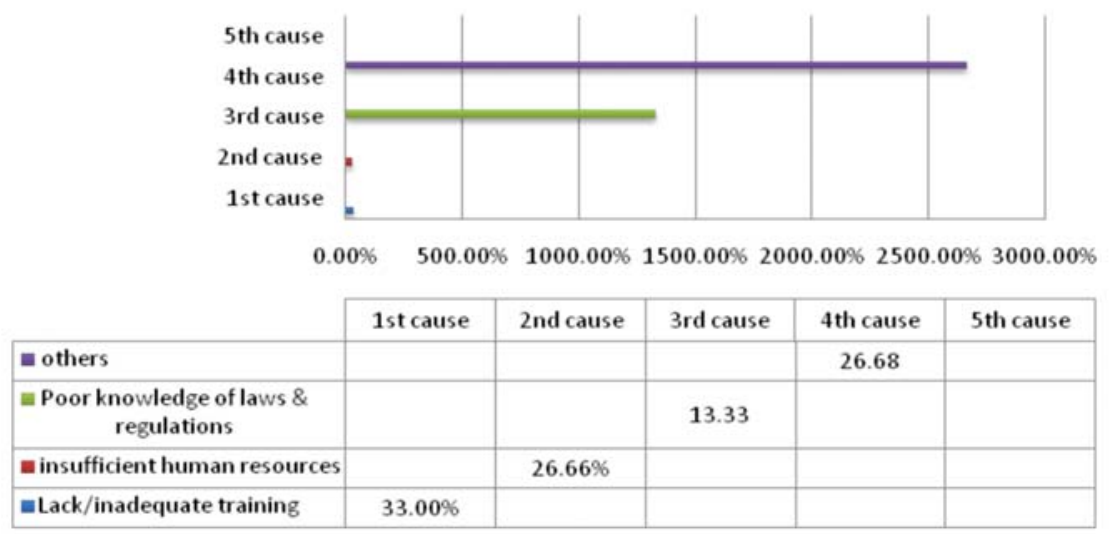

Figure 2.8. Barriers to the Effectiveness of Local and Central Authorities' Employees

Source: Authors' computation from the survey.

\section{RECOMMENDATIONS}

Given the results of the survey exercise, it is necessary to restructure the implementation system as a starting point, followed by a change of strategy on building regulations by the central authorities both at the policy development and implementation levels. The national government and the parliament should urgently work together to draw from the experience of neighbouring countries such as Nigeria and Ghana to put in place a specific and country-tailored Building Code with clearly prescribed technical and procedural requirements covering the whole building process from the planning stage to the building completion and including specific codes on enforcement. The Building Code should be placed under a single authority that would be responsible for overseeing all parts ranging from technical to procedural features, including the energy and environmental requirements. Without such instruments, the building practice will remain flawed, and any rule or regulation will still difficult to enforce.

It is recommended that all stakeholders should be fully involved in the development of the Building Code to make them take ownership of the end product. Such bottom-up approach to policy development 
would lead to a greater implementation rate once the policy is enacted. The central authorities should take lead in this direction and liaise with national and international organizations that possess expertise in such projects. This multilateral strategy in the development process would lead to a Code that is designed in accordance with the current international trend and which integrates under the building laws and regulations all matters pertaining to energy-efficient policies, increased fire resistance and environmental protection features. With such clearly defined features within the Code, all stakeholders would be in a position to clearly identify what is expected of them and to verify even before any inspection is done whether they are compliant or not.

Furthermore, the central and local authorities should undertake active information campaigns in order to raise the awareness of the local population on the existence of building laws and regulations, as well as their importance and the benefits of complying with them. That sensitization work can be done by developing adequate educational programmes for the youths within the national curriculum and by holding regular local area meetings with adults.

Also, strategies should be developed to reward those who comply, whether through taxation or any other means, and applying strict and severe penalties against breach of the regulations. Where it is considered necessary or expedient to do so, all available powers under the existing building laws and regulations must be used to control unauthorized developments.

In the same vein, regulators should streamline the procedures that the local authorities use for obtaining the various statutory planning permits. A successful review of those procedures would lead to lighter bureaucracy and encourage stakeholders to be more compliant. A review of the application fees related to those procedures would also contribute to avoiding the much-deplored corruption and enhance the compliance rate.

The central government, through its relevant ministries (such as Ministry of Town Planning, Ministry of Territorial Administration, Ministry of Energy, Ministry of Environment and Ministry of Health) should allocate adequate resources in the funding of local councils with the aim of providing sufficient resources to implementers.

Also, the local authorities should establish adequate records both for enforcement and compliance. That would significantly put pressure on stakeholders to comply with rules and render the implementers' actions more effective and accountable. 
It is also recommended that significant effort be put into research on the country's housing situation as clearer insight would shed light on the existing issue and assist in the development of a thorough and realistic policy and implementation strategy. Other authors have previously linked the chaotic situation of the housing to the lack of research. ${ }^{24}$

\section{CONCLUSION}

The building sector in developing countries, especially in West African countries, is quickly adapting to the reality of the modern era with the required duty to act sustainably and to construct buildings which will remain safe for occupiers' use and easily adapt to energy pressure and climate change agenda. Developed countries have put in place various instruments as recommended internationally to ensure that policies are developed with the safety and sustainability elements in mind, and appropriate strategies are inserted in those instruments (Building codes for most) for their effective implementation.

Unfortunately, the laws and regulations of the building sector in many African countries, including Cameroon, still remain inadequate; hence buildings continue to fail daily. The failures are mainly attributed to the poor or non-observance of the existing regulations even though it can be argued that they are not quite fit for their purpose. The results of the investigation carried out in this research show that various factors contribute to the poor implementation of existing building laws and regulations. The lack of awareness of the regulations by all categories of stakeholders is the most important judging by its highest average rate in the survey and the repeated reference to it by all respondents. Overall all the stakeholders surveyed and interviewed identified other important factors preventing effective implementation of the building regulations as including cultural change resistance, bureaucratic procedures, inadequate financial and human resources, shortage of qualified personnel, inadequate training of personnel, inadequate legal and regulatory instrument (too vague, and not tailored to the country's specific needs) and corruption.

This state of affairs appears to emanate from the policy development level. Indeed, it appears that the laws and regulations of the building

24 Njoh Ambe (n 8). 
sector in the country are developed without proper integration with the local context. The policies resemble extraordinarily those applied in countries such as France and do not seriously take into consideration the local reality. Policy-makers should be encouraged to apply the Contextual Interaction Theory method advocated by Owens and Bressers ${ }^{25}$ to re-energize the existing regulations for a better outcome.

The existing policies and regulations should be streamlined and simplified and, where possible, a full building code dealing with both planning and building controls should be developed and introduced so as to establish a coherent and objective achievement of the realistic goals set. Without such an approach, the expected outcome would remain low or unachieved.

25 Katharine A. Owens \& Hans Bressers, "A Comparative Analysis of How Actors Implement: Testing the Contextual Interaction Theoryin 48 Cases of Wetland Restoration" (2013) 15 (3) Journal of Comparative Policy Analysis: Research and Practice, 203-219. 